\title{
EXPERIMENTAÇÕES NA FORMAÇÃO DO EDUCADOR-PESQUISADOR: práticas de pesquisa e escrita acadêmica ${ }^{1}$
}

\author{
Marcia Cavalcanti Raposo Lopes \\ Escola Politécnica de Saúde Joaquim Venâncio - EPSJV/FIOCRUZ, Brasil \\ Luiz Antonio Saléh Amado \\ Universidade do Estado do Rio de Janeiro - UERJ, Brasil
}

\begin{abstract}
Resumo
Este artigo problematiza a formação do educador-pesquisador. Entendemos que o ato de pesquisar é intrínseco à atuação do educador. Tomamos como objeto de análise as práticas envolvidas no trabalho de formação na pós-graduação stricto sensu. Neste sentido, discutimos a aprendizagem e a formação, a partir da noção de invenção e problematizamos a produção do saber científico e seus efeitos sobre a subjetivação de alunos e professores. Por fim, buscamos deslocamentos no processo formativo da pós-graduação a partir da discussão das estratégias metodológicas da pesquisa e do estímulo à produção de textos acadêmicos, nos quais os estudantes foram convidados a explorar os limites entre a escrita acadêmica, a arte e a criação.
\end{abstract}

Palavras-chave: Formação na pós-graduação; Pesquisa em educação; Escrita acadêmica.

\begin{abstract}
This article problematizes the training of the educator-researcher. We understand that the act of research is intrinsic to the educator work. We propose to analise the training work practices developped in postgraduate courses. We discuss learning and training concepts from de notion of invention. We also problematize the production of scientific knowledge and its effects on the subjectivation of students and teachers. Finally, we seek displacements in the post-graduate training process from the discussion of the methodological strategies of research and the encouragement to the production of academic texts, in which students were invited to explore the limits between academic writing, art and creation.
\end{abstract}

Keywords: Postgraduate training; Education research; Academic writing. 


\section{Introdução}

Em geral, pouco se discute sobre a formação na pós-graduação. No entanto, o trabalho que ali se realiza merece atenção, pois as formas como produzimos conhecimento estão intrinsecamente relacionadas às maneiras como entendemos e agimos sobre o mundo. Neste texto, nos propomos a analisar as práticas pedagógicas na pós-graduação em educação, entendendo que os cursos stricto sensu não devem formar apenas pesquisadores para o mundo acadêmico. Problematizamos tais práticas considerando a formação de educadorespesquisadores envolvidos no cotidiano de seu campo de atuação, de modo que possam ser capazes de estranhá-lo e, mais do que responderem a perguntas já propostas, possam ser capazes de produzir novas perguntas.

Para tanto, fazemos uma discussão sobre o que é produção científica no campo da educação, colocando em questão a noção de ciência positivista e a sua pretensa neutralidade. Em tempos de obscurantismo, contudo, é importante afirmar que esta discussão não pretende ignorar a importância do conhecimento científico. Ao contrário, é baseado neste conhecimento, mas a partir de um outro olhar sobre ele, que colocamos em análise, em seguida, a maneira como entendemos a aprendizagem e a formação na pós-graduação.

Esta discussão nos permite trabalhar com algumas brechas nos procedimentos próprios dos cursos stricto sensu, com vistas a favorecer transformações em suas práticas pedagógicas. Uma dessas brechas surge no momento da discussão sobre a metodologia científica a ser usada nas pesquisas desenvolvidas pelos estudantes, quando o conceito de implicação permite colocar em questão as exigências de objetividade e neutralidade. Outra brecha se apresenta quando o aluno se envolve com o processo da escrita acadêmica e com as reações que ele evoca. Sobre este ponto, expandimos mais nossas análises a partir de uma proposta experimental para o trabalho final de uma disciplina, no qual os estudantes deveriam desenvolver um texto livre das rígidas regras acadêmicas.

Com este percurso esperamos contribuir para estimular análises e experimentações nos processos formativos das pós-graduações, em especial das pós-graduações em educação.

\section{É preciso discutir a ciência}

Vivemos tempos estranhos. Tempos que nos exigem cautela ao direcionarmos críticas ao conhecimento científico e aos dogmas e verdades que dele decorrem. Com a ascensão das forças políticas de perfil ultraconservador em diversos países pelo mundo, o saber científico passou a ser objeto de desprezo e de ataques diretos por parte de grupos que recusam os conhecimentos proporcionados pela ciência ao longo dos tempos. Esses grupos negam até mesmo verificações empíricas e se posicionam de maneira insólita, por exemplo, afirmando o terraplanismo e negando as alterações climáticas.

Reconhecemos o perigo de que as críticas ao modelo de cientificidade instituído reforcem os discursos obscurantistas que vêm ganhando espaço na sociedade nos últimos anos (notadamente com a eleição de D. Trump nos EUA e de J. Bolsonaro no Brasil). Por 
isso, a importância de marcarmos as diferenças entre os posicionamentos anticientíficos e os que buscam colocar em análise a ciência. Os primeiros, por motivos diversos, negam sistematicamente o conhecimento produzido pela ciência, enquanto os últimos, com os quais nos alinhamos, buscam de modo crítico problematizar o caráter incontestável e neutro frequentemente associado aos resultados alcançados por intermédio de metodologias científicas e experimentais. O objetivo de quem partilha deste posicionamento não é, portanto, o de negar a ciência, fechando-se a qualquer tipo de debate ou avaliação dos processos utilizados para a obtenção do saber, mas sim o de defender outros modos de produzir conhecimento ou, ainda, outras concepções de cientificidade.

Feitas essas observações iniciais, retornamos ao nosso tema de interesse, a formação do educador e do pesquisador em Educação. Com base no trabalho que desenvolvemos na graduação e na pós-graduação, pretendemos tomar como objeto de análise as práticas de pesquisa, a fim de problematizar a formação acadêmica do pesquisador em Educação, entendendo que o ato de pesquisar é intrínseco à sua atuação.

Ao chegarem à pós-graduação, os alunos tendem a reproduzir uma determinada noção de pesquisa científica associada ao modelo predominante de produção de conhecimento na nossa sociedade - o modelo racional positivista. Este modelo apoia-se na ideia de que o conhecer possui, basicamente, dois polos: um mundo prévio e um sujeito transcendental, e que a pesquisa científica tem como finalidade representar esse mundo o mais fielmente possível. Neste sentido, acredita-se ser necessário - e possível! - controlar as situações experimentais e suas variáveis, bem como separar objeto e sujeito do conhecimento. Na busca por alcançar o conhecimento objetivo, criam-se métodos e instrumentos com a intenção de eliminar incertezas, imprecisões ou qualquer tipo de interferência que possa colocar em risco a neutralidade e a objetividade do conhecimento produzido.

Ao discutir o surgimento da "universidade da investigação", Jorge do Ó (2019) nos lembra que o nascimento da instituição escolar moderna foi acompanhado da fantasia de que o conhecimento se deduz racionalmente e que no ensino moderno não há espaço para a dúvida. Com base na pesquisa histórica que empreende, nos mostra a relação entre as práticas de estudo nos colégios e universidades jesuítas e a construção da matriz curricular da nossa sociedade, consolidada no século XVI. Ele prossegue afirmando que a cultura escolar à qual estamos sujeitos se fundou sobre o medo de tudo que pudesse levar à fuga do pensamento e que, por meio de seu dispositivo educacional os jesuítas contribuíram para a organização do que ele chama de "tecnologia da ortodoxia e da exactidão do pensamento escolar". Jorge do Ó (2019) completa:

$\mathrm{O}$ aluno foi incessantemente concebido como aquela figura que é intimada e intimidada a ter apenas ideias adequadas, que dia após dia deve exercer o melhor das suas faculdades sobre um objecto que se supõe ser sempre o mesmo, que apenas procura respostas para perguntas e problemas já sancionados (p. 361).

Ao final do século XVIII, contudo, ganha força em países como França e Alemanha o movimento pela revisão permanente do currículo universitário, reivindicando a produção de 
conhecimento inovador. Segundo Jorge do Ó, diversos diagnósticos críticos foram produzidos com este objetivo, porém, dentre os que utiliza para ilustrar suas análises, cabe destacar o produzido por Chaptal (1756-1832), ministro do Interior de Napoleão, que apontava alguns vícios do sistema educativo de sua época: "as corporações conservam, mas não aprimoram nem inventam"; as corporações ensinam "como verdades as opiniões consagradas por uma longa tradição na escola" e o mais importante de todos, o de "comandar despoticamente a crença dos alunos nas ciências e na moral; de nunca propor a dúvida, a única capaz de excitar e desenvolver as faculdades do entendimento" (Chaptal, 1799, apud Ó, 2019, p. 363). Apesar de terem sido expostas há mais de dois séculos, as críticas ao sistema educativo de então permanecem bastante atuais. Deste modo, o autor conclui que devemos "continuar a zelar pelo registo vital da interrogação, pela multiplicação dos diálogos hesitantes, das formas dinâmicas e não terminais de circulação da linguagem” (Ó, 2011, p. 369).

Este movimento de revisão do currículo, referido acima, acontece na esteira de outro mais amplo, o Iluminismo, que induziu mudanças políticas, filosóficas e intelectuais, além de alterar significativamente o pensamento científico. Impulsionadas pelo movimento iluminista, as ciências da natureza irão se consolidar, graças à utilização de novos procedimentos - experimentação - e novas tecnologias - instrumentos de medição e observação. Elas vão colocar em questão, por exemplo, as lógicas e as verdades vigentes, até então, sustentadas na "tradição" da sociedade, herança de uma época dominada pelo discurso religioso ou místico. Porém, se o pensamento científico ganhou força interrogando as certezas naturalizadas e inquestionáveis, à medida que as ciências da natureza se desenvolviam e produziam discursos de verdade, os vínculos estabelecidos com os demais campos de saber, e com a sociedade de modo geral, foram se constituindo a partir de novas relações de poder. O saber científico, a partir de então, baseado no determinismo, nas relações de causalidade e na objetividade, ajudará a difundir a crença de que quanto mais a ciência se sofistica, mais se torna capaz de oferecer uma representação verdadeira do mundo. Não será difícil perceber, portanto, o controle que os saberes e as práticas discursivas e não discursivas advindas dele exercem, criando regras, estabelecendo limites, separações e domínios entre sujeitos e objetos do conhecimento, pois, como nos mostrou Foucault, todo saber pressupõe e estabelece relações de poder.

Desse modo, criaram-se as condições para que os procedimentos de investigação utilizados pelas ciências da natureza - seus instrumentos e técnicas - se tornassem referência de metodologia científica para as demais áreas de conhecimento. Ademais, difundiu-se a ilusão de que a aplicação de procedimentos metodológicos amparados nos rígidos controles científicos, por si só, permitiria eliminarmos as incertezas e alcançarmos a "verdade" sobre os fenômenos investigados. Paralelamente, parece que o sistema educacional foi reconduzido ao final do século XVI, de tal modo que, conforme já apontamos acima, apoiados em Jorge do Ó (2019), no ensino não pudesse haver margem para dúvidas.

Um conjunto de práticas discursivas e não discursivas, no qual as práticas religiosas têm um lugar fundamental, compunham o dispositivo que ajudou a forjar a instituição escolar de certo período histórico. Neste sentido, assistimos também a como se produziu uma nova 
subjetividade, juntamente com novos processos cognitivos, próprios à racionalidade científica que se difundiu com o iluminismo.

De acordo com P. Veyne (2011), a ciência está apoiada sob um dispositivo composto por regras, tradições, poderes, entre outros, e que impõe o cumprimento à risca de programas determinados. Entre os efeitos destes dispositivos estão: o jogo que permite separar os enunciados verdadeiros dos falsos, segundo regras específicas de formação dos discursos, regras essas submetidas ao crivo do saber científico instituído, e a produção de subjetividades correlatas ao racionalismo cientificista. Como afirma Veyne, "esse dispositivo forma, ao mesmo tempo, o objeto 'ciência' e os indivíduos que só reconhecerão uma verdade naquilo que é dito em conformidade com as regras de uma ciência exata" (2011, p. 152).

Não se pretende discutir aqui a eficácia dos saberes científicos para lidar com as questões sobre as quais se debruçam. Não obstante, a relevância de determinadas descobertas científicas para humanidade produziu o apagamento de outra importante descoberta proporcionada pelo pensamento científico: a necessidade do exercício da dúvida em relação às verdades naturalizadas. E é justamente a hesitação e a interrogação que advêm da dúvida o que têm permitido conhecer nossos limites e nossas possibilidades diante do mundo, sobretudo diante de problemáticas como as do corpo biológico ou das que envolvem os fenômenos físicos, domínios estes pertencentes ao campo das ciências da natureza. Além disso, a racionalidade valorizada pela ciência desconsidera que a aprendizagem e o conhecimento humano se produzem a partir de diferentes experiências e sensibilidades, que acabam relegadas pela lógica científica.

Há, contudo, diferenças fundamentais entre os domínios das ciências da natureza e os domínios do que se convencionou chamar ciências humanas. Tendo como objeto de conhecimento o próprio homem, observamos aí uma questão da qual não se pode escapar: de acordo com o pensamento científico positivista, que pressupõe a separação entre sujeito e objeto do conhecimento, como garantir a cientificidade de um campo de saber que tem, ao mesmo tempo, como objeto e como sujeito, o homem?

Na tentativa de solucionar o problema, as ciências humanas baseadas no modelo racional positivista de ciência procuram desenvolver técnicas e procedimentos que visam garantir a separação entre sujeito e objeto do conhecimento. No entanto, se esta separação é limitada até mesmo nas ciências da natureza, configurando um exercício de ficção (científica!), é nas ciências humanas que verificamos com mais clareza que tanto o objeto quanto o sujeito do conhecimento se constituem num processo de coengendramento.

Outro aspecto a ser destacado se refere às condições de emergência das ciências humanas. Foucault (1989) já havia nos mostrado a relação entre a liberação epistemológica das ciências que tinham como objeto o homem e as técnicas disciplinares. Por meio dessas técnicas, que permitiam o controle do espaço e do tempo; os registros e as anotações, constituiu-se o indivíduo "como objeto descritível, analisável", propiciando, ao mesmo tempo, as comparações, as medidas, a estimativa de desvios e a distribuição estatística. A entrada do indivíduo no campo geral do discurso científico, em fins do século XVIII, mantendo-o permanentemente sob controle do saber, é o "momento em que as ciências do 
homem se tornaram possíveis, é aquele em que foram postas em funcionamento uma nova tecnologia do poder e uma outra anatomia política do corpo" (FOUCAULT, 1989, p. 172).

A constituição do que se convencionou chamar ciências humanas, é necessário dizer, está associada também à aceitação de que a metodologia de investigação adotada por esta área de conhecimento deve ser a mesma preconizada pelas ciências da natureza. P. Veyne (2011) destaca que a observação dos fenômenos físicos, objetos das ciências "ditas exatas", permitiu detectar regularidades, repetições destes fenômenos, distinguindo-os do devir humano. São precisamente estas regularidades o que leva às aplicações técnicas, às previsões e aos desenhos experimentais. Porém, adverte ele: "tantas coisas na natureza são enumeráveis e calculáveis! A partir desses sucessos espetaculares, dessas verdades experimentalmente demonstráveis, não devemos concluir, porém, por uma harmonia preestabelecida entre nosso espírito e a natureza" (Veyne, 2011, p. 142).

Mesmo o campo aparentemente sólido das ciências da natureza assiste a movimentos no seu interior reivindicando outra visão da ciência, problematizando seus métodos, procedimentos e discursos. Em estudos desenvolvidos por I. Stengers (1990) e I. Prigogine e I. Stengers (1992), por exemplo, se discute o poder concedido à racionalidade científica, colocando em análise o ideal determinista. Tais estudos destacam o papel dos sistemas instáveis - os sistemas longe do equilíbrio - na relação entre determinismo e probabilidades, entre reversibilidade e irreversibilidade. De acordo com estes autores, a ciência vem redescobrindo o tempo, o que talvez nos permita outras possibilidades de conhecimento científico. No entanto, Prigogine e Stengers (1992) declaram não se tratar de:

[...] propor uma "visão científica do mundo" que pudesse unificar ciência e filosofia, suprimir as diferenças e as tensões. Qualquer que seja seu conteúdo, uma "visão científica do mundo" é por definição fechada, cheia de certezas, privilegiando as respostas em detrimento das perguntas que as suscitaram. Gostaríamos de fazer compartilhar não uma 'visão do mundo', mas uma visão da ciência. Da mesma forma que a arte e a filosofia, a ciência é antes de tudo experimentação criadora de questões e de significações (p.20).

Com base nessas análises e problematizações, acreditamos na possibilidade de outros caminhos metodológicos e de outras práticas de pesquisa para as ciências humanas, o que nos permite desenvolver um tipo de trabalho na pós-graduação, e mais especificamente no nosso campo de atuação, a Educação, a partir do qual o aluno pode estabelecer novas relações com o pesquisar e com a produção de conhecimento.

Efetivamente, isso envolve um debate que deve ir muito além de uma discussão metodológica. As formas de conhecer, a produção de conhecimento, não podem ser entendidas separadas de uma determinada forma de cognição e, consequentemente, da produção dos sujeitos. Problematizar as maneiras como temos trabalhado os processos cognitivos e os espaços de aprendizagem, torna-se aqui ponto fundamental para esta discussão. 


\section{Aprendizagem, pensamento e formação}

Buscando repensar a formação do pesquisador em educação e problematizar os processos de produção de conhecimento, é necessário colocar em questão algumas noções naturalizadas nas teorias pedagógicas tradicionais e assim abrir espaço para discutir os processos formativos na pós-graduação.

Se recuperarmos as teorias pedagógicas do século vinte, veremos, como aponta Gallo (2017), que elas se vinculam à noção de que só se aprende aquilo que é ensinado e que, portanto, pode-se controlar o que, o como e o quanto alguém aprende. Esta máxima parece estar presente em nossos movimentos de ensino-aprendizagem e na forma como, de maneira geral se organizam os currículos dos cursos de pós-graduação.

Uma ideia de pesquisador e de conhecimento acadêmico parece arraigada em nós. Como diz o próprio Gallo (2017), tomamos o processo educativo a partir de uma perspectiva "científica" que nos oferece segurança e parâmetros sobre como ensinar e como avaliar o aprendizado de cada um. "A questão é que este controle sobre o aprendizado, através do ensino, leva a uma homogeneização: o objetivo é que todos aprendam as mesmas coisas, da mesma maneira" (pg 104/105). E como escapar desse movimento? Como investir numa formação que favoreça encontros com a diferença, que possam suscitar estranhamentos, abalos e oscilações nos formandos e nos mundos que compartilhamos? Como favorecer que os caminhos trilhados por aprendizes e mestres possam desembocar simultaneamente em invenções de mundo e de si.

Buscando justamente nos provocar a avançar nestas questões, propomos nos aproximar das noções de formação inventiva (Dias, 2009) e de cognição inventiva (Kastrup, 1999). Consideramos que tais noções ajudam a embasar a nossa caminhada rumo à formação de pesquisadores que não tenha como ponto central a introjeção de um conjunto de regras acadêmicas a serem indiscriminadamente seguidas.

A proposta de formação inventiva apresentada por Dias (2009) não obedece a um formato, ao contrário, ela aposta na experimentação e tem como compromisso propiciar uma atitude cognitiva de problematização. Ela é pensada a partir da concepção de cognição inventiva de Virginia Kastrup. Sustentada por uma discussão de aprendizagem embasada na filosofia da diferença de Gilles Deleuze, esta concepção nos permite olhar para os processos de formação a partir de lógicas diversas do que estamos acostumados.

Segundo Katrup (1999) é possível mobilizar diferentes experiências de aprendizagem seja em processos educativos formais seja em informais. Para a autora, a cognição pode se constituir a partir de processos de recognição e de invenção. Os dois processos são importantes, mas têm efeitos distintos e complementares. O primeiro, a que estamos mais habituados e que é largamente tematizado pela psicologia, se atém à apreensão de informações e à resolução de problemas. Se nos restringimos a ele, investimos apenas no movimento de adaptação ao mundo e abrimos mão da potência de transformação dos processos cognitivos. O segundo se caracteriza por seu aspecto inventivo e suscita a possibilidade do sujeito de inventar a si e ao mundo.

Como escrevem Sordi e De-Nardi (2009): 
De um lado, temos as experiências de recognição que permeiam nosso cotidiano e nos permitem o reconhecimento dos objetos e de operações entre os mesmos de modo que possamos ter um bom desempenho diante das situações com as quais nos deparamos. São elas que nos dão condições de solucionarmos nossos problemas mais imediatos. Por outro lado, a cognição não se esgota na repetição e na solução do problema, mas se potencializa na capacidade humana de problematizar e na sua atividade inventiva que elimina o determinismo do objeto ou do ambiente (p. 73).

Os processos de recognição são extremamente valorizados no conjunto da formação escolar e parecem se tornar quase exclusivos em boa parte da formação acadêmica na graduação e na pós-graduação. Neles o que prevalece é um certo processamento de informação, a passagem do não-saber ao saber. Já a aprendizagem inventiva envolve a sensibilidade e o estranhamento. A experiência de problematização, se produz quando somos forçados não a assimilar conteúdos diversos que nos são transmitidos, mas a construir novos domínios cognitivos.

Kastrup (2001) usa o exemplo de uma viagem para explicar melhor esta questão. Quando alguém viaja a um lugar com hábitos e cultura diferentes dos nossos, mesmo atividades cotidianas podem tornar-se problemáticas.

Ao ser bruscamente transportado para um novo ambiente, os hábitos anteriores não servem e o viajante vive sucessivas experiências de problematização. [...] Quando viajamos somos forçados a conviver com uma certa errância, a perder tempo, a explorar o meio com olhos atentos aos signos e a penetrar em semióticas novas (p. 17).

A viagem produz uma ocasião de aprendizagem e essa aprendizagem prolonga seus efeitos e sua potência de problematização de tal maneira que quando retorna, o viajante está sensível a paisagens e situações que antes lhe passavam desapercebidas e que passam também a produzir estranhamentos.

Buscando desenvolver um pouco mais a noção de aprendizagem inventiva, Kastrup (2001) vai buscar no livro de Deleuze sobre Proust suas referências. Segundo o autor, aprender é considerar uma matéria ou um objeto como se estes emitissem signos a serem decifrados, sendo o signo um tipo de qualidade, de essência ou diferença que existe no seio de qualquer matéria e que exerce sobre a subjetividade uma ação direta. Aprender envolve tornar-se sensível aos signos emitidos pela matéria, eles podem ser extraídos da madeira, de um corpo doente, dos ingredientes usados para cozinhar, por exemplo ao se aprender marcenaria, medicina ou culinária, respectivamente.

Entendida desta forma, a aprendizagem não terá no sujeito cognoscente o seu centro, ela não se definirá a partir de uma relação entre um sujeito e um mundo composto de objetos. 
Sujeito e objeto são efeitos, e não pontos de partida ou pólos pré-existentes, pois o signo se expressa numa matéria, mas não é objetivo; afeta o sujeito, mas não é subjetivo. Sem ser objeto de recognição, força o movimento da subjetividade (Kastrup, 2001, p. 20).

No acaso dos encontros, somos tocados pelo signo. Ele nos atinge de fora, sem sabermos qual o seu sentido. Possui a força de uma interrogação que nos constrange a pensar. Impõese, dessa forma, como inevitável, produzindo a experiência que chamamos de problematização. Não é a procura pela solução de um problema dado, mas a própria invenção do problema. É deste processo que decorre a busca, sempre singular de solução e de sentido. Como afirma Deleuze (2000):

O pensamento só pensa coagido e forçado, em presença daquilo que 'dá a pensar', daquilo que se há de pensar - e o que se há de pensar é do mesmo modo o impensável ou o não pensado, isto é, o fato perpétuo que 'nós não pensamos ainda' (p. 247).

Dessa forma, aprender não pode ser entendido apenas como assimilar, (re)presentar ou reproduzir o que já está dado; aprender é criar, inventar, modificar a si mesmo e aos outros. Aprender envolve entrar em contato, em sintonia com os signos, relacionar-se, deixar-se afetar por eles, na mesma medida em que os afeta e produz outras afecções. Sem as amarras da objetividade e da racionalidade científica, esta noção de aprendizagem nos traz interessantes substratos para repensarmos a formação do pesquisador educador e nos afastarmos de uma formação calcada nos modelos instituídos pela concepção tradicional de ciência.

A cognição que trata o aprender pela problematização coloca as trocas e as experiências cotidianas no coração do projeto formativo. Ela traz para o centro da cena a sensibilidade do corpo, a abertura à imprevisibilidade e o fazer-se dos processos pedagógicos. Coloca-nos o desafio de repensar nosso trabalho docente menos pelos conteúdos e mais pela potência dos encontros.

Como nos coloca Dias (2009), discutindo a formação docente a partir de seu conceito de formação inventiva:

Formação de professores é pensada por aquilo que move os encontros, no meio dos quais há tensão e possibilidade entre os diferentes modos e formas de pensar e de fazer o conhecer. O desafio é tomar o conhecer como invenção de problemas, abrindo-se para as imprevisibilidades e pequenas invenções que emergem dos contextos de formação (p. 167).

Faz-se necessário então nos colocarmos o desafio de escapar de um processo predefinido de formação e investir na produção de um corpo sensível e atento ao plano de forças e afetos. Evidentemente, esse investimento não se dá a partir de transmissão de informações, como nos mostra Kastrup (2019): 
Há um tônus atencional a ser permanentemente calibrado, evitando os extremos de tensão e de relaxamento. Embora façamos um esforço para descrevê-la, tais sutilezas não podem efetivamente ser ensinadas por um professor que transmite informações. (p. 102).

No processo de ensino-aprendizagem, o papel do professor torna-se, então, acompanhar cuidadosamente o seu estudante. O ponto de chegada deste processo é marcado pela imprevisibilidade. "Colocar o problema, sustentar o problema, desenhar e redesenhar o campo problemático são os desafios" (Ibidem: 102).

Dessa maneira, a formação se constrói no cotidiano, quando as práticas ganham vida. As aulas, as orientações, as trocas, os processos de análise e construção de textos ganham forma e movimento, de acordo com o uso que se faz deles. A formação se constitui buscando escapar às formas deterministas e coercitivas e abrir espaço para o cultivo da experiência atenta, para a sensibilização aos afetos, enfim, para as aprendizagens que nos discentes, e também nos docentes, produzem diferenciações continuamente. Ela se constitui, portanto, como espaço de experimentação.

\section{Experimentações na pós-graduação}

Os estudantes que ingressam na pós-graduação trazem noções acerca da pesquisa científica que reproduzem o formalismo metodológico das ciências naturais. Entretanto, não é difícil encontrar brechas por onde iniciar um trabalho capaz de promover deslocamentos nestas noções. Logo nos primeiros encontros com eles, nas disciplinas ou nas reuniões de orientação, percebemos que as questões relativas à metodologia de pesquisa estão entre as que mais os inquietam. Em geral, a sensação de incapacidade para definir estratégias metodológicas ou escolher técnicas e instrumentos de pesquisa fala de certa insegurança em função das exigências impostas por este nível da formação acadêmica, mas diz também da preocupação em garantir que o produto de seu trabalho de investigação seja reconhecido pela academia. Esta é uma das oportunidades mais frequentes para problematizarmos aspectos como a eventual falta de conhecimentos ou a inexperiência no que se refere à pesquisa. Mas é também um momento propício para investirmos na produção dos estranhamentos, na invenção, para enfatizarmos os processos e menos o ponto de chegada. É um momento para colocarmos em análise os métodos científicos instituídos e ousarmos a construção de outros modos de pesquisar, outros modos de produzir conhecimento.

\section{Práticas de pesquisa e as implicações com certos modos de ver e pensar}

Na pesquisa, no trabalho, assim como no cotidiano, nos deparamos com inúmeras situações, diversos fenômenos, que sugerem regularidade, repetição e permanência. Apesar 
disso, basta deslocarmos minimamente nosso olhar para percebermos que a diferenciação está presente, que a bifurcação é frequentemente uma possibilidade. Entretanto, um dos efeitos das metodologias científicas instituídas, baseadas na lógica racional positivista e nas suas estreitas relações com a linguagem estatística e os procedimentos experimentais, parece ser o de apagar ativamente as diferenças. A extensão das leis estatísticas aos fenômenos naturais acabou por levar à construção de uma racionalidade conceitual que sustenta a afirmação de que "a regularidade subjaz à variabilidade aparentemente desordenada dos fenômenos" (Rose, 2011, p. 87). A adoção dos procedimentos metodológicos das ciências da natureza induz, portanto, o uso de lentes construídas para detectar regularidades e não o que é incerto, inconstante; as repetições e não as variações.

Esse modo de pesquisar está atrelado, segundo entendemos, a um pensamento representacional, à ideia de que investigar é descrever com precisão a realidade, representála fielmente. Todavia, as práticas que buscamos instaurar junto aos alunos e orientandos na pós-graduação tentam ir noutra direção, ao afirmarem a possibilidade de construção de novos sentidos, ao investirem na potência de criação que a pesquisa em educação pode comportar.

O incentivo para que o educador que pretende desenvolver um trabalho de investigação não se restrinja aos procedimentos metodológicos instituídos, tem relação com a certeza de que se percorrermos tão somente os caminhos trilhados por outros, tenderemos a chegar ao mesmo lugar. O processo de formação do pesquisador, mas também do educador, passa pela possibilidade de transformação, pela abertura para que outros modos de ver e pensar se agenciem aos processos de constituição da subjetividade.

Nesse esforço, todos nós - alunos e professores, orientandos e orientadores -, precisamos analisar as implicações dos diversos vínculos - profissionais, políticos, emocionais etc. - que mantemos com o sistema institucional ${ }^{2}$. Não é difícil percebermos, por exemplo, os efeitos que os atravessamentos de instituições como a educação ou a pesquisa científica têm sobre nós e nossas práticas, de modo que, ignorando-os, estaremos sujeitos a reproduzir em nós mesmos e em nossos alunos e orientandos as mesmas lógicas que muitas vezes criticamos. Decorre daí que analisar como tais vínculos se manifestam na prática cotidiana de trabalho ou de pesquisa é uma tarefa que pode apresentar grandes dificuldades, mas, apesar disso, deve ser levada a cabo individual e coletivamente. Vale destacar que não se trata de avaliar se alguém está mais ou menos envolvido com suas atividades acadêmicas. Trata-se, isto sim, do necessário questionamento acerca dos efeitos que os atravessamentos institucionais têm sobre nós, sobre nossos corpos, sobre nossas subjetividades. Implicados, todos estamos, como nos lembra R. Lourau (2004). Partindo do princípio de que nossas pesquisas, por mais assépticas que se pretendam, sempre irão produzir algum tipo de intervenção nos agentes envolvidos, assim como no campo sobre o qual incidem, o sociólogo e analista institucional nos alerta:

O útil ou necessário para a ética, a pesquisa e a ética da pesquisa não é a implicação - sempre presente em nossas adesões e rechaços, referências e não referências, participações e não-participações, sobremotivações e desmotivações, 
investimentos e desinvestimentos libidinais... -, mas a análise dessa implicação (Lourau, 2004, p. 190).

O exercício da análise da implicação, portanto, se configura como estratégia fundamental durante a atividade de pesquisa, abrindo caminho para a desconstrução de um dos discursos de verdade mais marcantes no campo da ciência positivista: a afirmação de que a ciência é neutra. $\mathrm{O}$ deslocamento provocado naqueles que se dispõem a analisar suas implicações com as instituições em jogo no trabalho de investigação não se reduz à mudança de uma posição que acredita na isenção da ciência para outra que considera impossível a neutralidade. Mais do que isso, a transformação que pode começar a surgir leva ao entendimento de que o processo de construção de conhecimento proporcionado pela pesquisa se beneficiará tanto mais quanto o investigador, e quem mais estiver envolvido na pesquisa, puder entender que o modo como nos vinculamos às instituições presentes em determinado campo de análise e de intervenção implica afetos, sensibilidades, análises, posicionamentos, conclusões. Enfim, a análise da implicação dos nossos vínculos peculiares com as instituições favorece os estranhamentos, amplia nossa potência de pensar e atuar frente às situações de pesquisa.

A busca permanente por criar espaços de liberdade que permitam ao educador experimentar outros métodos de pesquisa, que não aqueles legitimados pela ciência instituída, objetiva fazer emergir novos sentidos, incentivar a invenção e a diferenciação.

É importante ressaltar, como foi dito antes, que a insegurança e a sensação descritas por muitos iniciantes na atividade de pesquisa de que lhes faltam conhecimentos já podem propiciar a inquietação necessária para que os deslocamentos ocorram. O estado de ignorância relatado pelos pós-graduandos pode corresponder ou não à realidade, mas, como bem observa Lazzarotto (2012), a constatação de que a ignorância presumida exista, de fato, nos informa menos acerca do não saber destes futuros pesquisadores do que de um saber adquirido e naturalizado durante a formação, de maneira que reproduzam o conhecimento. De todo modo, a inquietação vivenciada pode ser o convite à experimentação e ao aprendizado de novos modos de conduzir a pesquisa, pois como lembra Lazzarotto (2012):

Os sentidos produzidos com a ignorância abrem caminhos para criação de um estilo próprio a ser experimentado, bem como um exercício ético que traz a liberdade de pensamento para afirmar uma ciência que se faz no encontro com a arte de viver (p. 102).

\section{A escrita do texto acadêmico e o trabalho do pensamento}

Além da insegurança diante das escolhas metodológicas, há outro momento que se destaca como brecha para produzirmos deslocamentos nos modos de pesquisar. Trata-se da escrita das dissertações e das teses, frequentemente motivo de questionamentos frente às exigências impostas pelas regras e normas acadêmicas e, por isso mesmo, fonte de ansiedade e insegurança. Para além disso, como registro oficial dos resultados de uma investigação ou 
mesmo dos pensamentos - certezas e incertezas -, o texto escrito, inegavelmente, expõe seu autor.

Não surpreende que, diante de tantas amarras metodológicas e de normas tão rígidas orientando a produção dos textos acadêmicos, os estudantes da pós-graduação experimentem bloqueios no momento que são requisitados a escreverem as dissertações ou as teses. Em geral, os modelos de gênero textual adequados à academia, como modelos que são, prescrevem estruturas e linguagens, resultando na redução substancial do espaço para a criação ou para a diferenciação. Paradoxalmente, a expectativa predominante na academia é de que as pesquisas desenvolvidas na pós-graduação se mostrem originais. Mas como produzir algo novo, diferente, se tudo o que é oferecido aos estudantes são formas, moldes e padrões? Com práticas assim, é possível alcançar algo além da repetição, da reprodução do que já foi pensado, feito ou dito?

Quando muito se avança, descobrem-se caminhos alternativos ou de maior criatividade ${ }^{3}$, mas que levam tão somente aos mesmos pontos de chegada alcançados por outros. Contudo, conforme dissemos acima, o ato de escrever tem sido mais um dos momentos de transgressão das subjetividades acadêmicas, moldadas segundo práticas que privilegiam a recognição. A aposta na potência do pensamento inventivo na formação dos educadores e pesquisadores em educação passa pela adoção de metodologias de pesquisa que favoreçam outras sensibilidades, outros modos de pensar. E passa, também, pela ação da escrita. Na "carta dirigida a um jovem investigador em Educação", Antonio Nóvoa (2015) expressa seu entendimento acerca do papel que a escrita pode desempenhar no trabalho acadêmico e, sobretudo, na constituição do pesquisador:

A escrita académica não é apenas um modo de apresentar dados ou resultados, é sobretudo uma forma de expressão pessoal e até de criação artística. Verdadeiramente, é no momento da escrita que se define o trabalho académico, que cada um encontra a sua própria identidade como investigador (p.17).

Entre os discursos que circulam na universidade, destacamos os de alguns outros professores de pós-graduação que também conferem importância à escrita no processo de construção de conhecimento, bem como na produção do próprio sujeito. Nos estudos que vem realizando sobre os espaços de educação e as tecnologias de subjetivação, Jorge do Ó (2019) critica o enfraquecimento da potência de criar enquanto, paralelamente, defende a liberdade de questionamento radical, do ceticismo e da dúvida. Na tentativa de compreender os processos presentes na constituição do investigador, o autor destaca que a "universidade do conhecimento e do pensamento inventivo" deve se dedicar a entender como se pode desenvolver estratégias para dar corpo à criação escrita e, ao mesmo tempo, para nos contrapor aos poderes atuantes nas instituições de educação, de maneira a evitar o bloqueio da "possibilidade de expansão democrática do gesto criador" (2019, p. 9).

Ao comentar sobre sua experiência na academia, seja como professora, seja como pesquisadora, Suely Rolnik (1993) expõe seu entendimento sobre o que vem a ser o trabalho do pensamento e como ele se realiza por meio da escrita. Segundo descreve, o trabalho com 
o pensamento, nomeadamente aquele que é desenvolvido numa prática acadêmica, sob a forma de estudo, escrita e ensino, está relacionado "às marcas, sua violência, nosso desassossego". Ela define as marcas como os estados novos, originais, que a vida produz em nosso corpo, acrescentando que, por estabelecerem diferenças, criam brechas para o surgimento de um novo corpo. Suely Rolnik prossegue, acompanhada por Deleuze, afirmando que só pensamos porque somos forçados a isso e que, portanto, seria um erro concebermos o pensamento como resultado da vontade que um sujeito dado tem de descobrir a verdade sobre um objeto dado. O pensamento resulta, isto sim, da violência provocada pela diferença. Como já afirmado pela autora, a prática acadêmica - da qual a escrita faz parte pode produzir marcas, desassossegos. Por isso, concordamos com ela quando afirma que "é na escrita que o pensamento rende o mais que pode: a escrita convoca o trabalho do pensamento, e lhe traz maior acuidade e consistência” (Rolnik, 1993, p. 8).

O terceiro exemplo de discurso presente nos meios universitários, voltado para a produção dos textos acadêmicos, é sustentado por Rosa Fischer (2005). Ela nos coloca diante de duas questões fundamentais. A primeira indaga sobre as relações possíveis entre o ato de produção do texto acadêmico e a experiência da criação e da fruição estéticas. Inevitavelmente, somos levados a pensar nos objetivos do texto científico, o que intencionamos com ele, a quem queremos atingir. Somos estimulados também a pensar no modo como nos apropriamos de conceitos, teorias e autores, e, consequentemente, se essa apropriação conduz à reprodução ou se encoraja a abertura de espaços para a criação e a invenção. A segunda pergunta que a autora nos faz questiona se os textos científicos podem - e mesmo se devem - comportar marcas autobiográficas do investigador. Esta questão nos leva a colocar em análise tanto os efeitos do que produzimos com nosso trabalho de pesquisa quanto o que este trabalho produz em nós. Ao mesmo tempo, impõe analisarmos nossas implicações, se entendemos a necessidade de ultrapassar os estreitos limites da concepção de uma ciência asséptica. Podemos concluir, junto com Rosa Fischer, que tais questões nos convocam a "pensar sobre fronteiras, limites e aproximações entre arte, produção científica e exposição de si mesmo" (Fischer, 2005, p. 118).

$\mathrm{O}$ ato de escrever e de pensar significa deslocar-se, tornar-se outro. Os textos produzidos pelos estudantes e pós-graduandos permitem ultrapassar a simples construção de textos visando a exposição de conhecimentos adquiridos ou dos resultados alcançados em suas pesquisas. Enquanto um dos elementos que contribuem para o exercício pessoal, os textos escritos produzem efeitos sobre seus autores, provocando o trabalho do pensamento sobre ele mesmo, a elaboração das experiências vividas, ou seja, a subjetivação destas experiências. E, segundo Foucault (2010), uma experiência é qualquer coisa de que se sai transformado.

Na discussão que fazem sobre a produção da escrita como estratégia formativa, Kastrup e Gurgel (2019) utilizam o exemplo da obra literária e seu autor, afirmando que este não antecede àquela, pois ambos são constituídos com base no mesmo processo de invenção. De acordo com as autoras, um processo formativo que inclua a escrita como experimentação permite o afastamento da experiência de recognição, proporcionando a percepção de uma dimensão que é marcada pela alteridade. Kastrup e Gurgel (2019) descrevem, então, como estas experiências são acionadas: 
Mobilizando a atenção ao presente, percebemos algo que não é conhecido, antecipável ou previsível, mas que ainda assim nos atravessa. A escrita, bem como a leitura que fazemos de nosso próprio texto, produz uma oscilação, algo como uma indecisão, uma tensão entre o si mesmo constituído e aquilo que o excede seu processo de produção. Essas estranhas experiências, que nos lançam na exterioridade de nós mesmos, se mostram capazes de transpor as barreiras de subjetividades já constituídas. (p. 69).

Apostando no potencial da escrita como experiência subjetivante, procuramos desenvolver um trabalho na pós-graduação, a partir do qual a produção textual seja objeto de atenção e cuidado, a fim de permitir que seu autor, o pesquisador em formação, tenha contato com aquilo que o processo de criação do texto escrito evoca, com as ações e reações surgidas. Acreditamos ser de fundamental importância desenvolver uma espécie de sensibilidade que faculte a percepção do que lhe acontece, do que lhe afeta, quando inicia uma etapa do trabalho acadêmico que é tão ou mais transformadora que as anteriores.

Movidos pelo interesse de trabalhar com a escrita do texto acadêmico como uma das estratégias para a construção de modos de pesquisar desobrigados do culto à neutralidade e da visão determinista da ciência instituída, ousamos introduzir certa provocação numa disciplina $^{4}$ do curso de pós-graduação onde um dos autores deste artigo leciona. Após transcorridas algumas aulas, convidamos os estudantes a produzirem seus trabalhos finais um texto escrito e individual - sem ficarem presos a formatações, nem a modelos acadêmicos preestabelecidos, senão expondo as afetações e as percepções vivenciadas nas atividades realizadas durante a disciplina.

É importante dizer que essa proposta não fazia parte da programação inicialmente construída. No desenvolvimento de pesquisas é preciso estar aberto e atento aos movimentos, ao inesperado, porquanto não existe planejamento capaz de prever todos os caminhos possíveis. Da mesma forma, no decorrer das aulas em uma disciplina é importante acompanharmos de perto os processos que vão se desenrolando. Assim, procuramos não negligenciar manifestações - verbais ou não verbais - que pudessem vir a enriquecer a proposta de trabalho.

As atividades previamente programadas - leitura de textos, seminários com professores convidados e dinâmicas discutindo temas do curso - dispararam movimentos e análises que nos instigaram a pensar nas estratégias que poderiam ser desenvolvidas a partir de então. Coerentemente com a proposta da disciplina - problematizar os percursos da pesquisa e da escrita como construção de si -, decidimos experimentar espaços de liberdade no que tange ao trabalho escrito, o que permitiu a exploração das fronteiras entre os textos acadêmicos, a arte e a criação.

Como podemos observar a partir dos $\operatorname{trechos}^{5}$ de alguns trabalhos entregues pelos estudantes, a provocação para que escrevessem textos que refletissem suas vivências durante a disciplina produziu deslocamentos interessantes. Praticamente todos os trabalhos recebidos demonstravam algum grau de problematização sobre a forma instituída de fazer pesquisa, 
bem como revelavam a franca disposição de alguns para a autoanálise, no sentido de colocar em questão o processo de se constituir aluno-educador-investigador.

Evidentemente, o espaço deste artigo não comportaria a inclusão dos trechos mais significativos de todos os trabalhos recebidos. Por esse motivo, a escolha recaiu sobre aqueles que pudessem dialogar de forma mais direta com as discussões efetuadas até aqui e ainda oferecer indícios sobre os possíveis efeitos que a proposta apresentada no âmbito da disciplina produziu. Nos trechos dos trabalhos selecionados encontramos depoimentos relativos à aprendizagem e à investigação científica, a noções como as de implicação e de subjetivação e, finalmente, à escrita acadêmica. Vemos desenhar-se um processo de aprender a ser pesquisador, não por assimilar métodos e técnicas, mas por desenvolver sensibilidades, deixar-se afetar pelos signos, por sua força, o que nos faz estranhar, interrogar, problematizar.

Iniciar os textos costuma revelar-se como o momento de maior dificuldade para aqueles que escrevem: "a paralisia diante da folha em branco", "as ideias que não vêm", são alguns dos relatos que exemplificam a sensação experimentada por inúmeros autores. A simples dispensa dos padrões acadêmicos para a construção do texto científico não é capaz de liberar magicamente o ato de escrever, como poderíamos supor. De acordo com o relato feito por K. Bastos em um dos trabalhos:

$\mathrm{O}$ silêncio que antecede o primeiro parágrafo anuncia - ou denuncia - o desconforto diante de um suposto começo do texto, muito embora, neste caso, não sejam exigidos os padrões acadêmicos dos mais rigorosos. Diante de tantas interrogações, impossível não abrir parênteses diversos, que movimentam, metalinguisticamente, questões a respeito da escrita de si. Isso posto, que não faltem a esta trajetória possibilidades de reticências (Bastos, 2019).

As prescrições e os padrões estabelecidos para a produção do texto acadêmico têm relação com critérios predefinidos para aceitação do trabalho científico, o que está diretamente associado às exigências de produtividade a que as pós-graduações estão submetidas. Seus efeitos, todavia, se somam às tensões originadas pela expectativa com os resultados da avaliação dos trabalhos, levando à despotencialização do pensamento e à redução da confiança para escrever. Além dessas questões, no trecho abaixo A. Dias apresenta em seu relato uma inquietação sobre o papel do tempo na organização do pensamento, na construção de sentidos. Verificamos, também, o condicionamento promovido pelas práticas escolares que, apoiadas na lógica positivista e no formalismo metodológico, contribuem para a modelização das subjetividades dos alunos, com efeitos na vida pessoal e profissional:

Tantos anos de escrita dentro de modelos pergunta-resposta, tantas prescrições, sentindo-me desautorizada a escrever e a questionar a partir de perspectivas diferentes, que pensar a escrita como processo de construção do eu-pesquisadora promoveu deslocamentos muito importantes nessa ainda curta trajetória de pesquisa. E como o mestrado tem passado rápido! Um ritmo muito intenso de leituras tão provocativas, que mexem tanto com os referenciais teóricos e de vida, 
causando tantos deslocamentos, e tão pouco tempo para absorver tantas questões que emergem (Dias, 2019).

Seguindo o caminho dos deslocamentos promovidos pela experiência proposta, C. Avelino fala dos "abalos" nos processos de pesquisa e de escrita. Ela descreve como percebeu o processo de construção do seu texto, revelando que ao reler suas anotações para a seleção do que deveria ser incorporado, foi transportada para as questões "que pulsaram durante nossas aulas". Segundo ela, as ressonâncias provocadas pelo curso, a acompanham desde então:

Sem o compromisso de relacionar estes registros a todos os textos lidos na disciplina e bastante afetada com as discussões feitas ao longo desta caminhada, tantas partilhas que circulam em mim, sinto que os debates coletivos me deslocaram em várias dimensões - pessoal, profissional, acadêmica -, dimensões que não são estanques e tampouco estão desarticuladas em mim (Avelino, 2019).

Mas os deslocamentos dependem de certa abertura para os signos, de disponibilidade para mudanças, da aceitação do estranhamento como possibilidade de perceber o que até então poderia estar diante dos olhos, mas não era visto. Esta disposição, que pode ser descrita como "atitude de abertura" (Fischer, 2005), é uma das características do investigador que modifica suas certezas e se deixa modificar. No campo da educação assistimos com frequência ao desenvolvimento de pesquisas que se debruçam sobre objetos naturalizados, que não admitem a dúvida como estímulo ao pensamento e que se dedicam apenas a confirmar o que já se conhece ou se supõe. Umas das consequências esperadas quando propomos estratégias como as da escrita livre para o texto acadêmico é exatamente propiciar a abertura para as mudanças, assimilando o estranhamento e possibilitando outros modos de pensar as questões da educação.

Os estranhamentos provocados pelas experiências nas aulas atingem variadas dimensões, certamente não são simples de serem assimilados e tampouco determinam alterações imediatas no repertório das práticas. Entretanto, acompanhando-se o relato contido em alguns trabalhos, certos efeitos puderam ser notados. Neste sentido, C. Avelino revela como a proposta da disciplina a fez pensar acerca da sua atuação junto à equipe técnicopedagógica multiprofissional do estabelecimento onde trabalha:

Os debates feitos foram bastante instigantes, desafiadores e plenos de potências. São contribuições significativas que estão me propiciando outros ângulos, o que, a meu ver, trazem também certo "frio na barriga" por desconstruir muitas das ditas "verdades", o que vejo como frutos positivos dessas aproximações (Avelino, 2019).

Falando também sobre estranhamentos, A. Muniz relata os desafios e riscos de se aventurar por campos de estudo e de pesquisa desconhecidos, mas, ao mesmo tempo, demonstra a disposição para percorrer novos caminhos: 
No fazer(se) da disciplina-ensaio estranhávamo-nos. Disciplina-ensaio como estilo e como estética: arriscava-nos, em agonística, em uma academia que está por vir; em vias de existir. Experimentávamos, a cada aula, nossas próprias escritas, os compartilhamentos, as sensações, as escutas. Um formato que, de alguma maneira, provocava intolerância às aulas-verdade e às meta-narrativas iluminadas (Muniz, 2019).

As atividades realizadas durante a disciplina parecem ter contribuído também para a colocação em análise de certos pressupostos que sustentam o modo instituído de pesquisar. No curso de tais atividades, estavam presentes questões que nos levavam a pensar nos nossos limites, por exemplo, para aceitarmos modificar as certezas que nos acalmam ou para liberar o pensamento do que já está instalado, pensado, silenciosamente, e abandonar a atitude tranquila de quem legitima o que já sabe (Fischer, 2005). Estranhar, acolher o inesperado, aceitar outros modos de pensar, especialmente se estes se opõem às verdades que nos foram transmitidas ao longo do percurso da nossa formação acadêmica, são atitudes do investigador cujo pensamento se abre à criação e à invenção.

Ao citar alguns dos pressupostos presentes em certos campos do conhecimento, $\mathrm{K}$. Bastos comenta que a ideia de totalidade remete a um olhar que necessita cobrir todo o campo, de modo a não deixar perguntas sem respostas. Neste universo de vigilância não é permitido correr riscos nem abrir brechas para o desconhecido. E, então, ela conclui:

A totalidade envolve caminho retilíneo e previsível, que parte do início e chega ao fim, muito provavelmente, confirmando hipóteses previamente estabelecidas e anunciadas. Assim, conhecemos um modo de fazer pesquisa que exige do pesquisador abraçar o todo que supostamente exista, evitando aproximações e tangenciamentos com o que possa haver além desse "todo" (Bastos, 2019).

É importante afirmar que a crítica aos modos instituídos de fazer pesquisa não representa apenas a disputa em torno do estatuto de verdade para tal ou qual discurso científico. Há nesta atitude a necessária marcação de uma posição política clara, no interior dos espaços acadêmico-científicos destinados à pesquisa, em defesa da produção de conhecimento que considere outros modos de pensar, de ser e de se conduzir. A esta constatação também parece ter chegado M. Silva quando afirma:

Sem dúvida, independentemente da ferramenta metodológica usada [...], causar fissuras no modelo hegemônico de se produzir pesquisa nas universidades é um ato político revolucionário, pois abre espaço para outros tipos de olhares para o mesmo objeto, assim como formas de se pesquisar e se permitir transformar (Silva, 2019).

A crítica ao modelo hegemônico de pesquisa na universidade como ato político nos coloca frente a uma questão da qual não podemos fugir: a implicação que mantemos com as 
instituições instrumentalizadas na formação e na atuação profissional. A fim de ultrapassarmos a mera disputa por posições de poder na academia, é necessário que analisemos que lógicas fortalecemos e que relações de força sustentamos com nossas práticas de investigação. Realizar a análise da implicação, portanto, é algo que deve ser feito ao longo das pesquisas, e a escrita é um dos momentos mais potentes para este movimento.

Quando descreve o processo de desenvolvimento de sua pesquisa, M. Silva deixa ver em seu depoimento os efeitos da análise da implicação por meio da escrita. Seu relato, porém, não fica restrito às justificativas lógicas ou políticas para sustentar a análise da implicação. Ela percebe também a importância dos afetos e admite que a análise do que nos constitui pode ser difícil, por vezes dolorosa, pois mexe com as marcas e até mesmo com o corpo, finalizando assim o relato:

Talvez por isso eu fuja tanto da escrita, mas ao mesmo tempo eu sinto que eu preciso falar sobre o medo, sobre como fui e sou afetada, porque o silêncio produzido por ele sufoca. O processo da escrita implicada é dinâmico, mas não é fácil porque ele pode ser doloroso, sem deixar de ter a sua beleza [...] entendo que durante a minha caminhada para a construção desta pesquisa um novo corpo já vem emergindo (Silva, 2019).

Impossível separarmos nossas vivências, aquilo que nos acontece, das análises e dos pensamentos, como se fôssemos capazes de separar corpo e mente. Somos parte de nossas pesquisas e elas fazem parte de nós. Não por acaso, ao descreverem sua experiência com a escrita, vários estudantes se referiram às marcas produzidas em seus corpos, evidenciando a ressonância provocada pelo conceito de marca, utilizado por Suley Rolnik (1993) quando esta apresenta sua perspectiva ético/estético/política no trabalho acadêmico. De acordo com a autora, as marcas são os estados inéditos que se produzem em nossos corpos, a partir das composições vividas. E continua ela: "cada um destes estados constitui uma diferença que instaura uma abertura para a criação de um novo corpo, o que significa que as marcas são sempre gênese de um devir" (1993, p. 2).

Em outra narrativa sobre o processo envolvendo a escrita e a pesquisa, A. Dias comenta que o ato de escrever a respeito dos trabalhos pedagógico e de gestão que realiza - objetos de sua pesquisa -, evidenciou as marcas adquiridas como profissional da educação. Ela percebe a dificuldade de romper com as práticas naturalizadas e afirma a importância da análise da implicação nesse processo:

As leituras, as discussões e orientações no grupo de pesquisa, assim como nas disciplinas cursadas, têm contribuído muito para transformar incômodos e as questões vinculadas a eles em objetos de análise e estudo, ajudando a desnaturalizar os modelos estabelecidos, os sistemas que estruturam as políticas de formação e os modos de produção dos sujeitos docentes e gestores. Não sendo esta uma tarefa fácil, pois construir esse afastamento e estranhamento das práticas conhecidas e em que estamos imersos no cotidiano escolar, me provocou a 
analisar, junto aos meus interlocutores nessa caminhada de escrita, as implicações envolvidas neste lugar de produção de formação continuada (Dias, 2019).

A provocação que fizemos para que os estudantes produzissem seus textos sem as amarras dos modelos acadêmicos, visava a problematização dos percursos da pesquisa e da escrita como construção de si. Essa espécie de exercício pessoal, em que pensamentos e impressões são expostos ao leitor, pressupõe a abertura às experiências vivenciadas. Com base nos estudos de M. Foucault (2004) sobre a escrita de si, desejávamos promover situações a partir das quais fosse possível ampliar a atenção sobre si e sobre as verdades que circulam nas práticas que nos constituem e que legitimamos. A proposta para a construção de um texto autoral, livre, partiu do pressuposto de que este tipo de escrita convoca o sujeito a se deslocar, a fazer uma experiência, nos termos que a define Foucault (2010). O filósofo nos revela que escrever seus livros eram, para ele, experiências transformadoras, pois modificavam o que ele pensava e o que ele era. E numa autêntica declaração de quem não apenas aceita mudanças, mas as deseja, afirma: "sou um experimentador no sentido em que escrevo para mudar a mim mesmo e não mais pensar na mesma coisa de antes" (Foucault, 2010, p. 289).

Possivelmente, quando aceitou a provocação feita durante a disciplina para produzir um texto acadêmico autoral, que incluísse suas vivências, M. Silva não podia dimensionar as dificuldades que enfrentaria ao estranhar pensamentos, sensações e práticas que lhe eram familiares até então. Se naquele momento algum desejo de mudança já estivesse presente, foi após o exercício da escrita que percebeu as transformações ou as metamorfoses como alternativas viáveis, pois, como explica:

[...] tentar produzir uma "escrita de si", é um processo metamórfico infindável não só da escrita, mas daquele que também escreve. Essa transformação acontece não só quando escrevemos, mas quando lemos inúmeros artigos e livros para aprofundarmos nossas pesquisas, quando pensamos sobre nossos objetos de pesquisas, quando passamos pelo silêncio na escrita, quando trocamos com nossos companheiros acadêmicos etc. Esse sentimento de estranheza e também de dor, devido às adaptações que tive que fazer, foi valioso para mim. Algumas vezes senti-me estranha como Gregor Samsa, de um grande clássico da literatura - A metamorfose, de Kafka -, com toda minha dificuldade para me adaptar ao novo corpo, mas essa metamorfose deixou mais claro que o corpo antigo não me cabia mais, não dava conta dos meus transbordamentos. Esse processo é infindável, e eu aprendi a gostar dele porque a flexibilidade nos ajuda a atravessar nossos dilemas, contradições, [...] de uma forma menos dolorosa a cada experiência vivida (Silva, 2019).

A referência à adaptação ao novo corpo que surge remete à ideia das marcas, conforme já citamos. Enquanto gênese de um devir, as marcas conduzem a escrita. Segundo S. Rolnik (1993), escrever sendo conduzido pelas marcas significa sermos transportados para o invisível e as palavras que encontramos "tornam o mais palpável possível, a diferença que só 
existia na ordem do impalpável. Nesta aventura encarna-se um sujeito, sempre outro: escrever é traçar um devir" (p. 9).

Os caminhos que levam à transformação nos modos de pensar a pesquisa não estão desconectados dos modos de ser e estar no mundo. Ao contrário do que certos discursos do campo psi sustentam, a subjetividade não está centrada no sujeito individual, em suas instâncias intrapsíquicas. Segundo Guattari e Rolnik (1986), os processos de subjetivação são constituídos pela conexão de instâncias variadas, pressupondo o funcionamento de sistemas sociais, tecnológicos, ecológicos, midiáticos, sistemas, enfim, de natureza extrassocial, assim como de sistemas de natureza infrapsíquica, como, por exemplo, sistemas fisiológicos, corporais, de percepção e de sensibilidade.

Momentos como os proporcionados pelas disciplinas, pelas orientações e, como destacamos neste texto, pela escrita acadêmica, podem favorecer o desenvolvimento da sensibilidade a novos signos, propiciar problematizações das práticas, produzir análises das implicações com os sistemas institucionais, facilitar a construção de novos sentidos. Dependendo da maneira como instrumentalizamos as relações e as estratégias de formação, tais espaços constituem oportunidades ótimas para avaliarmos como vivemos a subjetividade: se reproduzimos modelos, a partir dos componentes de subjetivação apresentados, ou se estabelecemos com esses componentes uma relação de criação, de invenção - singularizando.

Propusemos uma experiência com a escrita acadêmica. Em seu texto, A. Muniz cria a noção de "escrita-experiência". Como ela própria afirma, com este tipo de escrita não se pretendeu refletir as existências, nem as representar, mas ousou-se experimentar outros modos de pensar e de se constituir a si mesmo:

Ao fazer da escrita-experiência uma intercessora no território da academia, não intencionávamos desvelar verdades, prescrever a melhor forma de produzir pesquisas ou mesmos manuais criativos de escritas. Fazíamos uma aposta éticopolítica nos modos de escrever(se) pesquisas-pesquisadores que, desviando-se da busca por uma pretensa neutralidade e expondo o "avesso da tapeçaria", podem produzir modos singulares de práticas de pensamento que interrogam o sujeito no interior das práticas hegemônicas de produção de conhecimento (Muniz, 2019).

A experiência com a produção do texto escrito, relatada em vários trabalhos recebidos, foi um retorno positivo a reforçar esta aposta. Em seu trabalho, A. Dias expõe os efeitos da proposta apresentada na disciplina, abrindo brechas para perceber as transformações ocorridas com ela e, ao mesmo tempo, recuperando forças para continuar enfrentando as questões que venham a surgir:

Esse estado interessante por estar prenhe do que se quer escrever/dizer vem acompanhado de uma insegurança de como fazê-lo, travando o fluxo da escrita [...], mas se colocar nesse fluxo de escrita tem sido muito importante para construir uma potência produtiva [...]. Neste trajeto coloco-me a refletir sobre os possíveis processos de singularização no caminho da escrita que foram construídos nos 
encontros que ocorreram no decorrer da disciplina "A pesquisa e a escrita como construção de si". Os referenciais ali discutidos, as falas dos colegas que viraram fragmentos registrados nos cadernos, nos cantos dos textos, foi onde encontramos espaço de recusa à subjetivação vigente e possibilidade de liberdade para viver, refletir e analisar nossos processos. Volto para a escrita da minha pesquisa com marcas atualizadas, deixando fluir as tantas questões que surgiram, que foram provocadas em tantos encontros e desencontros da pesquisadora do início e da pesquisadora em curso (Dias, 2019).

\section{Considerações finais}

No trabalho que desenvolvemos em cursos de graduação e de pós-graduação, temos apostado em práticas de formação do educador e do pesquisador pautadas na concepção de que aprender não se resume à representação do que é dado. Aprender inclui a sensibilidade do corpo, a abertura às experiências cotidianas e ao imprevisível. Esta noção de aprendizagem permite a criação e a modificação de si mesmo e do mundo, além de possibilitar as condições para um outro tipo de formação do pesquisador em educação, não submetido aos ditames da objetividade científica.

Seja qual for o campo de conhecimento a que uma pesquisa esteja vinculada, as regras e os métodos científicos não devem se sobrepor à liberdade dos investigadores para criarem, para transgredirem. A disposição para assumir riscos, para ousar, é fundamental para conseguirmos pensar de outro modo. Se não houver transgressão não haverá descoberta, nem criação; não haverá ciência (Nóvoa, 2015).

Sabemos que a formação do pesquisador requer a aquisição e o domínio de conteúdos, e no campo da educação não é diferente. Em razão disso, buscamos orientar os estudantes no sentido de que construam os conhecimentos necessários para sua formação. Entretanto, em nosso trabalho na pós-graduação, investimos, fundamentalmente, na potência dos encontros, acompanhando o estudante no processo de seu desenvolvimento como investigador, pois, como afirma Jorge do Ó:

[...] é a coexistência, o estar-junto e em relação-com que permite a lenta afirmação dos sujeitos de ciência. Só dessa forma se poderá dar corpo a essa transmutação — não isenta de riscos mas entusiasmante aventura - do aluno, que todos fomos, em investigador, que todos desejamos vir a ser. Sair da lógica da reprodução escolar do conhecimento e familiarizar-se com os métodos e processos da sua criação (Ó, 2019, p. 10. grifos do autor).

Por mais que nos esforcemos, jamais conseguiremos controlar o que ou como os estudantes aprendem. Imaginar que só aprendem o que ensinamos, já se mostrou um grande equívoco. Nos caminhos trilhados por aprendizes e mestres, mais do que os conhecimentos que domina e pode transmitir, o professor transmite um certo modo de se relacionar com as questões da pesquisa e da formação. Ao investirmos mais nos encontros, na abertura à 
experiência e ao estranhamento, estaremos nos aproximando, talvez, do professor descrito por Suely Rolnik (1993), não como o sábio, mas como o aprendiz, como o que cria. No entanto, não devemos supor que esses aprendizes de pesquisador reproduzam os passos e os pensamentos do mestre, pois:

O que este professor aprendiz/criador visa com seu ensino é autorizar e suscitar no aluno este aprendiz/criador, que evidentemente não será igual à sua pessoa e não falará nem das mesmas coisas, nem com o mesmo estilo, já que o que se produz desde esta posição é necessariamente singular, pois singulares são as marcas que conduzem esta produção e o estilo é exatamente esta singularidade encarnada (Rolnik, 1993, p. 12).

A proposta para que os estudantes, futuros pesquisadores, desenvolvessem um texto autoral, livre, objetivava dispensá-los das prescrições que impõem métodos científicos rígidos, que limitam até mesmo a construção dos textos acadêmicos e que terminam por dificultar sobremaneira a possibilidade de invenção. Ao permitirem que as experiências vivenciadas na disciplina e nas pesquisas até ali fizessem parte das análises, os estudantes foram se deixando conduzir pelas marcas em seus corpos. Neste exercício, um duplo movimento pôde ser observado: o de se deixar estranhar e de construir outros sentidos.

No processo da escrita dos textos, solicitamos também que não se pautassem pela objetividade nem pela neutralidade, a fim de que pudessem se libertar dos condicionamentos que direcionam a vigilância para as respostas esperadas. Desse modo desejávamos favorecer a abertura às novas questões que costumam emergir em qualquer pesquisa. Em diversos relatos pudemos notar que um processo de transformação estava em curso. Apoiados na análise das implicações e, portanto, sem o compromisso de se apresentarem neutros e objetivos, os estudantes não necessitaram sustentar o questionável distanciamento em relação ao que se dedicavam a investigar.

A aposta no potencial da escrita como experiência subjetivante parece ter contribuído para o aprendizado de outros modos de pesquisar. É possível que nesta experiência, todos nós, aprendizes/criadores, tenhamos exercitado certo distanciamento, desde que seja aquele descrito por B. Latour (2008) quando se refere à ciência que promove algum distanciamento entre os conteúdos do mundo antes e depois da investigação; aquela que estabelece alguma distância entre o repertório de ações que apresentamos ao final e aquele com o qual iniciamos a pesquisa. 


\section{Notas}

1. Trabalho realizado no contexto do convênio CAPES-Print.

2. De acordo com a Análise Institucional, instituições podem ser definidas como lógicas - leis, normas ou mesmo hábitos - que regulam os comportamentos (BAREMBLITT, 1992). Ou ainda como forma geral das relações sociais que se instrumenta em estabelecimentos e em dispositivos (RODRIGUES e SOUZA, 1987), produzindo e reproduzindo tais relações.

3. Cumpre dizer que não utilizamos neste trabalho o termo criatividade como sinônimo de invenção ou criação. A criatividade, sob o ponto de vista da Psicologia, faz parte da inteligência mais geral, e se refere à capacidade de solucionar problemas dados. No caso da invenção, a imprevisibilidade está presente sempre, não há uma meta. A invenção se volta para a colocação de problemas (KASTRUP e GURGEL, 2019).

4. A disciplina em questão, intitulada "A pesquisa e a escrita como construção de si”, foi oferecida em parceria com a professora Estela Scheinvar e é uma disciplina eletiva do Programa de Pós-Graduação em Políticas Públicas e Formação Humana, um Programa interdisciplinar, da Universidade do Estado do Rio de Janeiro.

5. A apresentação dos trechos selecionados com vistas à discussão proposta neste artigo foi autorizada pelas autoras.

\section{Referências}

BAREMBLITT, Gregório. Compêndio de Análise Institucional e outras correntes. Rio de Janeiro: Rosa dos Tempos, 1992.

CHAPTAL, Jean. A. Rapport et project de loi sur l'instruction publique. Paris: Imprimerie de Crapelet, 1799.

DELEUZE, Gilles. Diferença e Repetição. Lisboa: Relógio D’Água Editores, 2000.

DIAS, Rosimeri de O. Formação Inventiva de Professores e Políticas de Cognição. Informática na educação: teoria \& prática. Porto Alegre, v.12, n.2, p. 164 -174, 2009. Disponível em: https://seer.ufrgs.br/InfEducTeoriaPratica/article/view/9313/7260. Acesso em: 01 de set de 2020.

FISCHER, Rosa. M. B. Escrita acadêmica: arte de assinar o que se lê. In: COSTA, Marisa. V.; BUJES, Maria. I. E. (orgs.) Caminhos investigativos III: riscos e possibilidades de pesquisar nas fronteiras. Rio de Janeiro: DP\&A, 2005. p. 117 - 140

Foucault revoluciona a pesquisa em educação? In: FISCHER, Rosa M. B. Trabalhar com Foucault: arqueologia de uma paixão. Belo Horizonte: Autêntica Editora, 2012. p. 99 - 112.

FOUCAULT, Michel. A Escrita de si. In: Ditos e escritos V. Rio de Janeiro: Forense Universitária, 2004. p. 144-162.

Conversa com Michel Foucault. In:

Repensar a política: Ditos \& escritos VI. Rio de Janeiro: Forense Universitária, 2010. p. 289 - 347.

Vigiar e Punir. Petrópolis, Editora Vozes. 1989.

GALlO, Silvio. O Aprender em Múltiplas Dimensões. Rev Programa Pós-graduação em Educação Matemática da UFMS. v. 10, n. 22, p. $103 \quad$ - $114,2017$. Disponível em:https://periodicos.ufms.br/index.php/pedmat/article/view/3491/3096. Acessado em: 01 de set de 2020.

GUATTARI, Felix. e ROLNIK, Suely. Micropolítica: cartografias do desejo. Petrópolis: Vozes, 1986.

KASTRUP, Virgínia. A Invenção de Si e do Mundo: uma introdução do tempo e do coletivo no estudo da cognição. Campinas, SP: Papirus, 1999. Aprendizagem, arte e invenção. Psicologia em Estudo, Maringá, v. 6, n. 1, p. 17-27, 2001. 
Disponível

em:

https://www.scielo.br/scielo.php?pid=S141373722001000100003\&script=sci_abstract\&tlng=pt. Acessado em: 01 de set de 2020. A atenção cartográfica e o gosto pelos problemas. Rev. Polis e Psique. 20 ANOS DO PPGPSI/UFRGS p.
$99 \quad-\quad 106$
2019.
Disponível

em:https://seer.ufrgs.br/PolisePsique/article/view/97450/55365 . Acessado em 01 de set de 2020.

KASTRUP, Virgínia. e GURGEL, Verônica. O papel da escrita na formação de professores e o problema da coemergência. In: DIAS, Rosimeri. de O. e RODRIGUES, Heliana. de B. C. Escritas de si: escutas, cartas e formação inventiva de professores. Rio de Janeiro: Lamparina, 2019. p. 60 - 71.

LATOUR, Bruno. Como falar do corpo? A dimensão normativa dos estudos sobre a ciência. In: NUNES, J. A., ROQUE, R. (Orgs.). Objetos impuros: experiências em estudos sociais das ciências. Porto: Afrontamento, 2008. p. 40 - 61.

LAZZAROTTO, Gislei. D. R. Experimentar. In: FONSECA, Tania. M. G. F., NASCIMENTO, Maria. L. do N., MARASCHIN, Cleci. Pesquisar na diferença: um abecedário. Porto Alegre: Sulina, 2012. p. 101 a 103.

LOURAU, René. Implicação e sobreimplicação. In: ALTOÉ, Sônia. René Lourau: analista institucional em tempo integral. São Paulo: Hucitec, 2004. p. 186 - 198.

NÓVOA, Antonio. Carta a um jovem investigador em Educação. Revista Investigar em Educação. 3, p. 1321. 2015. Disponível em: http://pages.ie.uminho.pt/inved/index.php/ie/article/view/83/82. Acessado em 01 de set. de 2020.

Ó, Jorge R. N. do. Fazer a mão. Lisboa: Edições do Saguão, 2019.

PRIGOGINE, Ilya. e STENGERS, Isabelle. Entre o tempo e a eternidade. São Paulo: Companhia das Letras, 1992.

RODRIGUES, Heliana. de B. C. e SOUZA, Vera. L. B. A Análise Institucional e a profissionalização do psicólogo. In: KAMKHAGI, Vida R. e SAIDON, Osvaldo (orgs.). Análise Institucional no Brasil: favela, hospício, escola e funabem. Rio de Janeiro: Espaço e Tempo, 1987. p. 17 - 36.

ROLNIK, Suely. Pensamento, corpo e devir - uma perspectiva ético/estético/política no trabalho acadêmico. Caderno de Subjetividade, São Paulo, v. 1, n. 2, 1993.

ROSE, Nikolas. Inventando nossos selfs: psicologia, poder e subjetividade. Petrópolis, RJ: Vozes, 2011.

SORDI, Regina.; DE NARDIN, Maria Helena. Contribuições de Francisco Varela ao Estudo da Aprendizagem Inventiva em Sala de Aula. Informática na educação: teoria \& prática, Porto Alegre, v.12, n.2, p. 82-92, 2009. Disponível em: https://seer.ufrgs.br/InfEducTeoriaPratica/article/view/9918/7246. Acessado em: 01 de set de 2020.

STENGERS, Isabelle. Quem tem medo da ciência?: ciências e poderes. São Paulo: Siciliano, 1990.

VEYNE, Paul. Foucault: seu pensamento, sua pessoa. Rio de Janeiro: Civilização Brasileira, 2011.

Como se escreve a história e Foucault revoluciona a história. Brasília: Editora Universidade de Brasília, 2008.

\section{Correspondência}

Marcia Cavalcanti Raposo Lopes: Mestre em Saúde Coletiva pelo IMS/UERJ; Doutora em Psicologia Social pelo PPGPS/UERJ. Professora-Pesquisadora da Escola Politécnica de Saúde Joaquim Venâncio/FIOCRUZ.

E-mail: marcia.lopes@fiocruz.br 
Luiz Antonio Saléh Amado: Mestre e Doutor em Psicologia Social pelo PPGPS/UERJ. Professor Associado da Faculdade de Educação da Baixada Fluminense (FEBF/UERJ). Professor Permanente do Programa de Pós-Graduação em Políticas Públicas e Formação Humana (PPFH/UERJ).

E-mail: $\underline{\text { saleh.amado@gmail.com }}$

Texto publicado em Currículo sem Fronteiras com autorização dos autores. 